\title{
RAÍCES HISTÓRICAS \\ DEL FEDERALISMO LATINOAMERICANO
}

de José Carlos Chiaramonte,

Buenos Aires, Sudamericana, 2006, 320 pp.

MAXIMILIANO FERRERO

Universidad Nacional del Litoral

Este nuevo libro del historiador José Carlos Chiaramonte se propone reconstruir a partir de una serie de artículos y extractos de conferencias, corregidos y ampliados, algunos conceptos clave del lenguaje político de las élites que condujeron los procesos de independencia latinoamericanos. Para ello, el autor reforzará algunas tesis que lo han convertido en una ineludible referencia para los estudios sobre los procesos de construcción de las identidades políticas durante el siglo XIx. La primera es que, en cuanto a las independencias latinoamericanas, y particularmente la rioplatense, la nación se encuentra más del lado de los efectos que de las causas. La segunda, hace referencia a una nueva interpretación del federalismo argentino y latinoamericano que pretende zanjar el hiato entre lo que denominamos federalismo y lo que en general se entendía por tal concepto, lo que el autor llama "confederacionismo", es decir, "la preferencia por esa antigua forma de organización política, la confederación, mediante la cual Estados soberanos que por diversos motivos necesitan unirse a otros lo hacen sin perder su independencia soberana» (p. 9).

De esta forma, podemos sostener que la preocupación central del libro es la de ofrecer una nueva interpretación de las transformaciones políticas latinoamericanas a partir de la diferenciación semántica entre el concepto de "confederación» tal como ya lo había explicado Montesquieu (en El Espiritu de las Leyes, IX, I) y el de «federación» o Estado federal, forma de organización política que inaugura la constitución de Filadelfia de 1787. Cabe agregar con dicho objetivo, el autor recurrirá a clarificar además una serie de 
conceptos que se conectan con el de federalismo como los de constitución, consentimiento, soberanía y retroversión.

El texto se encuentra dividido en tres partes y siete capítulos. La primera se denomina «Las independencias anglo e hispanoamericanas» y está formada por dos capítulos que versan sobre las formas que adoptó el federalismo en las ex colonias británicas y sobre las características de los estudios superiores en estos territorios, respectivamente. Estos capítulos se asientan en la idea de que para obtener una mejor comprensión de los fundamentos institucionales e intelectuales de las independencias latinoamericanas, es menester compararlas con las colonias del Norte. En referencia a la primera cuestión, Chiaramonte sostiene que los puntos de partida al momento de la independencia son cabalmente diferentes, puesto que cada una de las colonias norteamericanas conformaba una suerte de república, en el sentido de que ya poseían al menos una rudimentaria división de poderes y procesos electorales establecidos. En las regiones de Hispanoamérica, por el contrario, los protagonistas de la independencia fueron ciudades que asumieron una soberanía vacante. El autor encuentra entonces que las prácticas representativas de las ex colonias británicas eran más proclives a la institucionalización de un sistema republicano. Su marco ideológico, un ideario político y jurídico de tradición anglo tendiente a la limitación del poder regio y la defensa de la libertad individual frente al Estado, cuyas bases pueden encontrarse en la antigua Carta Magna (I215) o en los juicios por jurados (II64).

En lo que respecta a las instituciones de enseñanza superior, la primera diferencia es que los colleges fueron creación de las propias comunidades que elegían a sus autoridades y sostenían su financiamiento, y no de la monarquía o de las órdenes religiosas como las universidades hispanoamericanas. Por otra parte, el propósito de los primeros se orientaba a la formación de una élite capaz de moralizar la conducta de los miembros de la sociedad a partir de los principios del puritanismo (no necesariamente hostiles al mundo de los negocios), mientras que las segundas se preocupaban en formar funcionarios coloniales para consolidar la estructura política de la monarquía. Por ello, se organizaron "como transmisoras de un corpus de saber que legitimaba las relaciones de poder requeridas por la monarquía» (p. 55).

La segunda parte del libro se dedica especialmente al estudio del federalismo rioplatense y está compuesta también por dos capítulos. En el primero, Chiaramonte analiza la convivencia ideológica que se produce entre variantes del pensamiento contractualista. Éstas servirán de fundamento al surgimiento de los gobiernos locales al proveer los argumentos necesarios 
para sostener la reasunción de la soberanía frente a un monarca cautivo. Así, el contractualismo de la antigua constitución española cuyo núcleo se encontraba en el principio del consentimiento y del pacto de sujeción a la persona del monarca, entrará en diálogo, por ejemplo, en la pluma de Moreno, con el pensamiento contractualista de El Contrato Social de Rousseau. En el segundo capítulo, después de repasar el proceso de formación de los nuevos sujetos soberanos, esto es los "pueblos», y su posterior institucionalización en provincias, Chiaramonte refuerza las dos ideas mencionadas en la introducción. No existen manifestaciones de un sentimiento de identidad más allá del ámbito provincial que hagan referencia a una nacionalidad argentina. Aunque aquí el autor distingue, por un lado, la cuestión de la identidad colectiva en la que los constituyentes provinciales suelen reconocerse como americanos, de la cuestión de la organización política que, frente a la posible unión de las distintas entidades soberanas, adquiere una delimitación es sí argentina o rioplatense. Dicha unión se da posteriormente al fracaso de la constitución centralista de I826 con el Pacto Federal de i83I, según el cual se establece una forma confederativa. Inmediatamente el autor pasa a corregir el equívoco, persistente hasta la actualidad, entre los conceptos de confederalismo y federalismo.
Es necesario diferenciar la confederación que se establece a partir del Pacto Federal de i83i del Estado federal que se crea a partir de la constitución de I853, así como en las colonias del Norte es también menester no confundir la confederación posterior a la independencia del Estado federal inaugurado por la constitución de I787. Así, por un lado, el concepto de confederación hace referencia a una asociación de Estados independientes que deciden unirse por alguna razón (por ejemplo, la defensa frente a un agresor mayor) y no pierden su calidad de entidades soberanas - por lo que continúan siendo sujetos de derecho internacional. Por otro lado, el concepto de federación refiere a la creación de un nuevo actor internacional, esto es, a un poder central que tiene jurisdicción sobre los habitantes de cada uno de los Estados miembros, en todo aquello que establece la constitución. A partir de varios ejemplos, Chiaramonte muestra además que el equívoco entre los usos de confederación y federación es habitual entre los mismos actores políticos.

La tercera parte del libro, denominada «El federalismo en otras regiones hispanoamericanas» se compone de tres capítulos y estudia de modo general la formación de los poderes regionales y la problemática organización de los nuevos Estados soberanos en el área hispanoamericana. En el primer capítulo el autor analiza los descontentos que generan en las colo- 
nias americanas las reformas perseguidas por los Borbones que tendían a afirmar la soberanía ilimitada del monarca y a la uniformidad de la administración de las colonias. Así, las causas fundamentales de ese descontento fueron la limitación de las prácticas de autogobierno de las ciudades americanas y la implantación de una nueva élite comercial, lo que despojaba a los criollos de posibilidades de acceder a los diversos niveles de administración, de la justicia o de la Iglesia. En el segundo capítulo, después de algunas observaciones semánticas sobre conceptos como «región», "provincia», "nación» y "federalismo», advierte que a partir de los procesos de independencia hispanoamericanos, emergen tendencias autonómicas «buscando afirmar su independencia o, en caso de considerar esto inviable, unirse a los pueblos vecinos en una organización política nueva» (p. 202). Muchas de estas entidades (ciudades o provincias) prefieren la unión confederal con el fin de mantener su cuota de soberanía frente a las ciudades principales del territorio. En general, lo que en estos países se ha llamado federalismo no fueron, sino «las tendencias a unirse por parte de los pueblos que emergieron como sujetos soberanos en el momento de la independencia» (p. 206). Finalmente, el último capítulo es un análisis de diversos casos que incluye a la Argentina, México y la Gran Colombia, entre otros. A partir de ellos, Chiaramonte busca fortalecer las ideas presentadas en los capítulos anteriores, fundamentalmente, la de no interpretar de la misma manera el inédito resultado de la constitución de Filadelfia y las tendencias confederativas propias de los nuevos sujetos soberanos que emergen como resultado de los procesos independentistas en Hispanoamérica. 